\title{
Luciano Floridi-Commentary on the Onlife Manifesto
}

\author{
Luciano Floridi
}

$\S 1.1$ The transformations mentioned in this paragraph may be understood in terms of a fourth revolution (Floridi 2012; Floridi Forthcoming) in our philosophical anthropology. After Copernicus, Darwin, and Freud (or neuroscience, if one prefers), ICTs (that is, Turing), are casting new light on our self-understanding. It may be preferable to speak of a informational era rather than a computational era, because it is the increasingly pervasive and ever more important life-cycle of information (from creation through management, to use and consumption, see (Floridi 2010) that deeply affect both individual and societal well-being. In a technical sense, computers and computation are only a small part of this wider phenomenon.

$\S 1.2$ There are much more nuanced and balanced interpretations of Modernity as a historical and cultural phenomenon, but the point here is not to offer a scholarly interpretation of a stage in the history of ideas. Rather, I understand the word "modernity" in the manifesto as a philosophical portmanteau (or linguistic blend) that combines into one word the bundle of concepts/phenomena discussed in this and the following sections.

$\S 1.3$ Paradoxically, the more ICTs advance, the more humanity appears responsible for how things go in the world (including in terms of forecasting and prevention of consequences and future event), and yet, the more difficult it becomes to identify specific sources of responsibility. Increasing levels of responsibility and co-responsibility are generating new challenges. Clearly, there is much need for understanding the new phenomenon of so-called "distributed morality" (Floridi 2013a, b).

$\S 2.1$ Modernity is also a pedagogical project: the intellectualistic (as in Socratic intellectualism: the view that people make mistakes because they do not know better) idea that more information (of all kinds, theoretical, technological, practical, etc., see the editorial project of the Encyclopédie) will lead to more learning, which in turn will lead to improved choices, and hence to a progressive amelioration of the human condition.

\footnotetext{
L. Floridi $(\bowtie)$

Oxford Internet Institute, University of Oxford, 1 St Giles, Oxford, UK

e-mail: luciano.floridi@oii.ox.ac.uk
} 
§ 3.1 What seems to be lacking, in affluent societies, is the fundamental engagement with the human project: the increasing amount of leisure appears to find our culture unprepared. It is as if, having worked hard to gain the right to be on vacation, humanity might then be uncritically unprepared to make the most of its most precious resource, time. Technologies are used to save time first, and then to kill it. So one of the pressing political questions that we are facing in advance information societies is: what sort of human project are we working on?

$\S 3.2$ The reader interested in knowing more about the idea of onlife may wish to consult (Floridi 2007).

$\S 3.6$ The distinction between public and private will probably need to be reconceptualised, because frameworks based on physical boundaries (the ever pervasive analogy of trespassing) and possession (the equally pervasive analogies of ownership and theft) are out-dated conceptual modules, insofar as they are linked to a modern or "Newtonian" metaphysics based on inert things and mechanical interactions.

$\S 4.1$ The reader interested in knowing more about the idea of the relational self may wish to consult (Floridi 2011).

$\S 4.4$ I suggested the phrase "Building the raft while swimming" in order to emphasise the radical nature of the philosophical task ahead of us, rather than stressing any anti-foundationalist philosophy. Understanding philosophy as conceptual design means giving up not on its foundationalist vocation, but rather on the possibility of outsourcing its task to any combination of logico-mathematical and empirical approaches. This was not Nueurath's intention when he first introduced the metaphor of the raft in the 1930s. As he wrote (Neurath 1959, p. 201 ): "There is no way of taking conclusively established pure protocol sentences as the starting point of the sciences. No tabula rasa exists. We are like sailors who must rebuild their ship on the open sea, never able to dismantle it in dry-dock and to reconstruct it there out of the best materials. Only the metaphysical elements can be allowed to vanish without trace. Vague linguist conglomerations always remain in one way or another as components of the ship."

$\S 4.5$ Rethinking and developing new forms of education are certainly among the most exciting challenges of our time. There are great opportunities, but also a serious risk of missing them. In the same way as we lack a post-Westphalian way of approaching politics, likewise we are still missing a post-Guttenberg way of approaching pedagogy. The difficulty is further exacerbated by the mental constrain imposed by the overbearing presence of the book for so many centuries, which makes it hard to consider alternative forms of education (think for example of the written assessment procedure); and by the omnipresence of ICTs, which constantly distract our reflection into believing that the real issue concerns which technical solutions are or will be more feasible to manage learning processes involving digital natives, when in fact the fundamental problem is not how but what: what kind of knowledge will be required and expected when living onlife.

$\S 4.6$ What is ultimately finite, precious, not-renewable, and unsharable is actually time. When talking about finite attentional resources, we should also be concerned with the attention-time dedicated to something, because that is neither boundless nor replaceable. 
Open Access This chapter is distributed under the terms of the Creative Commons Attribution Noncommercial License, which permits any noncommercial use, distribution, and reproduction in any medium, provided the original author(s) and source are credited.

\section{References}

Floridi, L. 2007. A look into the future impact of ICT on our lives. The Information Society 23 (1): 59-64.

Floridi, L. 2010. Information - a very short introduction. Oxford: Oxford University Press.

Floridi, L. 2011. The informational nature of personal identity. Minds and Machines 21 (4): 549-566.

Floridi, L. 2012. Turing's three philosophical lessons and the philosophy of information. Philosophical Transactions A (370):3536-3542.

Floridi, L. 2013a. Distributed morality in an information society. Science and Engineering Ethics 19 (3): 727-743.

Floridi, L. 2013b. The ethics of information. Oxford: Oxford University Press.

Floridi, L. Forthcoming. The fourth revolution - the impact of information and communication technologies on our lives. Oxford: Oxford University Press.

Neurath, O. 1959. Protocol sentences. In Logical positivism, ed. A. J. Ayer, 199-208. Glencoe: The Free Press. 